\title{
Online Delivery Of Programmes: A Case Study Of IGNOU
}

Ramesh Sharma

\begin{abstract}
Online education is the most exciting segment in the Indian IT space. A host of e-education sites continue to enter the market with focused offerings, linking up students and teachers, almost on a daily basis. This is happening because the new medium seeks to supplement - not replace - traditional teaching-learning methodologies. Keeping in view the global and in country/domestic market changes, India has to play a vital role in terms of software exports, skilled manpower support, and online education. With India currently in the midst of a "dotcom" wave, Indira Ghandi National Open University (IGNOU) has taken the initiative in launching online in January 2000 two of its educational computer programmes. In July 2000 it launched twenty capsule courses (each comprising three courses) in different specialization areas of management [http://www.ignou.com/index.htm]. Each of these capsules addresses one specific functional or specialization area, one basic course pertaining to that specialization and a project course. The Bachelor of Information Technology and Advanced Diploma in Information Technology programmes are offered through a Virtual Campus Initiative (VCI). Management Programme capsule courses are offered through Project MEIDS (Management Education through Interactive Delivery Systems).
\end{abstract}

\section{Organisation of the Case Study}

This paper describes various issues and concerns experienced in the launching of online delivery at Indira Ghandi National Open University (IGNOU). First, distinguishing features of IGNOU are explained, in terms of significance, establishment, instructional system, academic programmes and modes of programme delivery. Various parameters that led to the initiation of online delivery of programmes in addition to the traditional print-based (offline) distance education programmes are given next, followed by the sequence of events in the emergence of the current format of delivery. This online programme delivery initiative has special consequences for IGNOU, learners and the delivery mechanism; these are explained next. This case study concludes with a discussion of the implications of such initiatives for IGNOU, and for the distance education system in the country as a whole (as IGNOU is the resource centre and apex body of distance education in India for nine other State Open Universities). 


\section{Introduction}

The establishment of IGNOU on September 25, 1985 by an Act of Parliament heralded the arrival of an important innovation in India. It provided a gateway to all those desirous of improving their qualifications and sharpening their academic skills, through the open and distance education system. In a relatively short period of 15 years since its inception, IGNOU has positioned itself among the top educational institutions in the country and in 1993 received the Centre of Excellence in Distance Education Award conferred by the Commonwealth of Learning.

IGNOU has now close to 600,000 students with varied profiles on its rolls, spread throughout the length and breadth of the country, and serves these students via a network of 44 regional and 630 study centres all over India. Taking a cue from IGNOU, some states have also established their own open universities. Currently there are nine state open universities and one National Open School along with full-fledged state open schools in Haryana, Andhra Pradesh, Kerala and Madhya Pradesh as well as separate departments within the State Board of Secondary Education in West Bengal and Rajasthan.

\section{Institutional Culture and Structure}

IGNOU is the first institution in India to offer programmes designed to meet the identified needs and interests of a wide variety of learners throughout India. No formal qualifications are required to study most courses. Almost anyone can be admitted into a programme, irrespective of previous education. In the event they are needed, preparatory courses are offered. Since students are drawn from the widest spectrum of backgrounds, age groups, geographical distribution and other socio-economic traits, learners can start and take as long as they wish to complete courses. Most programmes are structured on a modular pattern with provision for multiple entry and exit points as well as mobility across and within programmes. To ensure low costs, the Government of India subsidizes most of IGNOU's study programmes.

To decrease learner isolation and to provide academic, administrative and informative support to learners, Student Support Services operates two types of support centres - regional centres and study centres. The latter play an important role, delivering self-learning course material and supplementary learning aids (audio, video, teleconference, interactive radio counselling, etc.) and providing opportunities for learners to enhance their learning through contact programmes.

To provide support services to learners in areas not having institution-based support facilities, individuals who have post-graduate degrees and who are per-

International Review of Research in Open and Distance Learning 
manent residents in given areas may serve as distance learning facilitators. They include retired teachers/officers, professionals, housewives, or even motivated unemployed individuals. Similarly, with the objective of extending the outreach of education on a single window basis (making all facilities available at one place), IGNOU in collaboration with the Indian Army, Indian Air Force and Indian Navy, has launched an educational project to cater to defense personnel in different parts of the country. For this purpose, Recognised Regional Centres have been established at the five Army Commands, seven Air Force Commands, and four Navy Commands.

Communication technologies play a pivotal role in IGNOU's instructional system. Multimedia packages prepared for learners incorporate a range of technologies: print, audiotapes (average two to four per course), videotapes (average one to two per course), interactive radio counselling, one-way video/two-way audio teleconferencing, television lessons, CD-ROMs, and Web-based content delivery, and so forth. On average, these form nearly $20 \%$ of a course. The Electronic Media Production Centre of the university, set up with a grant from Japan Government, prepares audio and video cassettes. Radio programmes are broadcast in the form of Interactive Radio Counselling (IRC) through All India Radio (AIR), a national government agency that serves $97 \%$ of the people in India through a network of 198 broadcasting centres [http://air.kode.net/about.html]. Besides IRC, video teleconferencing is available to learners at the study centres through the Indian Space Research Organisation's (ISRO) Training and Development Communication Channel.

To take advantage of the common resource pool and to avoid duplication of effort, some state open universities use course materials produced by IGNOU (Sharma, 1999). Academic telecounselling of nearly all IGNOU programmes is shared by some state open universities (Sharma).

The Ministry of Human Resources Development provides maintenance and development funding to IGNOU. Development funding is provided in two parts - for IGNOU's infrastructure developments and programmes, and for development of State Open Universities. IGNOU has also received support from such international agencies as Overseas Development Agency of UK, the Commonwealth of Learning, and the Japanese International Cooperation Agency.

With respect to its maintenance funding, IGNOU is unique in that: (a) Compared to any traditional university in the country, income earned in the form of student fees, sale of admission prospectus and other publications, and so forth is substantial; and (b) as a proportion to the total annual revenue expenditure (operating costs), maintenance grants from Government subsidies are progressively declining. Since its inception, there has been a steady increase in the number, range, variety, and diversity of the programmes launched by IGNOU. The university has grown from 2 programmes and 4,528 students in 1987 to more than 60 programmes, 600 courses and 200,000 students in 2000. With this expansion in programmes and enrolment, the income-generating capacity of the 
university has increased considerably.

\section{Launching Online Delivery: Issues, Efforts and Events}

IGNOU offers popular and successful print-based programmes, namely Master of Business Administration, Master of Computer Applications, Bachelor of Computer Applications, and Certificate in Computing, enrolling more than 100,000 students. Different extra-institutional factors and institutional environmental demands (e.g., spread of Internet to many cities of India, new technological developments, etc.) have led IGNOU to experiment with transforming the university into a global virtual university whereby it may make learning opportunities available through the click of a mouse to anyone, anywhere, anytime. In 1998, the university authorities decided to provide services to learners in the new technological format at their own desk. This approach was thought of as a way to remove at least three types of tyrannies - spatial, temporal, and fixed curriculum. It was realized that through the Internet, course content would be equally available to learners, irrespective of their geographical locations. Similarly learners would not be forced to learn at fixed hours of the day.

To realize the dream of removing the spatial, temporal and fixed curriculum tyrannies, the university collaborated with the Edexcel Foundation (a UK registered charity), to provide education and training. Two Web-centric programmes were launched, namely the Bachelor of Information Technology (BIT) and Advanced Diploma in Information Technology (ADIT) under a new project called Virtual Campus Initiative (VCI), whereas the School of Management Studies offered MBA degree programmes, post graduate diploma and capsule courses with online support through a project called Management Education through Interactive Delivery Systems (MEIDS). Both these projects are explained in the next section. Other grounds that led to the initiative of launching online delivery are geography, economics and competition, all described below.

\section{Geography}

India is a vast country with many languages, cultures and so forth. There are difficult terrains ranging from the desert in Rajasthan, to the snow-capped mountains in the Himalayas, and the Southern Plateau. To serve its learners in all these regions, the Faculty of Computing Sciences and Management Studies recommended the online mode of delivery as a viable medium. At the same time, computer networking was being established both nationally (at the district level by the Government of India), and in the university (in 1997) at all the regional centres by linking them through e-mail and the Internet. The Vice-Chancellor

International Review of Research in Open and Distance Learning 
appointed a committee (headed by a Director) to look after the progress in this regard. The IGNOU headquarters were thus connected with its regional centres via the Internet. Once this basic infrastructure was created, in 1998 university management decided to deliver the programmes and services through the Internet. Examination results also began to be relayed by e-mail to the regional centres, thus further reducing the time factor. Thus the university was considered adequately equipped to adopt the new mode of online delivery.

\section{Economics}

The mode of material distribution in IGNOU has been constantly changing. Establishment of regional warehouses and sending material by post involved huge costs. Both students and study centres complained of late receipt or non-receipt of material in some cases. The School of Computer Sciences and Management Studies saw offering courses via the Internet as a way to lower various costs involved in production and distribution of course materials. Study materials could be made available simultaneously for students to download from the WWW, thus reducing the time and cost of shipping materials to all places.

\section{Competition}

New educational providers have recently entered the Indian educational scene. Examples include (a) training organizations in the private sector (e.g., information technology), (b) professional areas such as management, (c) development of on-the-job education and training establishments, and (d) various foreign institutions. To keep pace with the technology and changing educational scenario, the Faculty of Computing Sciences and Management Studies decided to provide student support services through the Internet.

\section{Diploma in Management}

In this era of knowledge explosion, management education is an area that is prone to rapid obsolescence as far as the ways and techniques of managing are concerned. The management programmes (Diploma in Management) were launched in 1987 with an initial enrolment of 2,800 students; the mode of delivery was print-based. The first cohort of 800 students finished in 1989. In 1999 the numbers enrolled had increased to 18,000. Another programme, the MBA in Banking and Finance, was started in 1999.

In that same year it became apparent that as long as continuing education programmes in management were limited solely to print-based delivery, the School of Management would not be able to meet the demand, particularly from clien-

International Review of Research in Open and Distance Learning 
tele who lived in areas where convenient access to study or learning centres is nonexistent. As a result, Management Education through Interactive Delivery Systems (MEIDS) was launched in 1999. Specific capsule courses for continuing management education, that is self-instruction courses providing synchronous and asynchronous interaction with experts via the Internet, were designed and launched in various functional areas (e.g., Human Resources Development, Human Resources Planning, Management Control Systems, Management of Information Systems, Marketing, Operations Management) in connection with the award of Diplomas, Post-Graduate Diploma and MBA Degree. This endeavour was designed to parallel the existing and mainly print-based and fully off-line MBA programme. Rather than replace print-based management programmes, the MEIDS project was designed as an additional effort to make management programmes accessible to those who could gain professional education at their own place aided with technology. The main objective behind MEIDS was to cut across the distance (via the Internet) and to simplify administrative processes (e.g., admissions) by automation whereby a student logs on to the site, pays the requisite fee and gets registered immediately. While admission to offline management programmes is through an entrance examination, admission to the programmes under MEIDS is relatively relaxed and for capsule courses only, no entrance test is required.

The Faculty of Management Studies proposed the programme be delivered through specifically identified Partners in Advanced Learning System (PALS) institutes, which have the approval of All India Council of Technical Education (an autonomous organization in India that sets norms for management, professional, technical and vocational courses). Possessing complementary resources, these management institutes were regarded as ideal starting points for networking and were designated PALS on the basis of applications solicited through advertisements or face-to-face discussion. They provided facilities for admissions, organizing counselling sessions through teleconference, examinations, and acted as local resource centres for the School of Management. Because these continuing education programmes in the form of short-term capsules were to be offered nationwide, the school proposed to its partners (a) complete computer Internet connectivity, (b) a suitable mechanism for electronic library access and data transfer (this electronic library was to be built up of full text articles, experiences and developments in industrial management and updated regularly), (c) counselling support through teleconferencing, and (d) self-instructional materials.

Following advertisement of admissions in newspapers in 1999, the first cohort of 128 students began capsule courses in January 2000; the second cohort of 141 students began in July 2000. The programme uses a multimedia approach consisting of self-instructional printed course material and relevant audio/video. Students collect their material from the PALS. As a means of student support, some relevant course material, assignments and question papers from previous years are available on IGNOU's Internet site and may be downloaded by students

International Review of Research in Open and Distance Learning 
using an ID and password. Currently in offline delivery mode (non-MEIDS) there are two tutor-marked assignments and one computer-marked assignment for management programmes, out of which the best two are counted for the final grade. But under the MEIDS project, two computer-generated assignments are administered online and evaluated by the computer. A protected site is used for student registration, assignment generation, assignment submission, digital reference materials, and evaluation. Assignments are made available on the WWW and downloadable course materials are available in HTML and MSWord formats. Students go to PALS to complete the assignments, consisting of multiple-choice questions. Results become available as soon as the student submits the completed assignment and grades are automatically transmitted to headquarters. Online entrance testing for admission to this programme is under consideration by the authorities.

Presently there are 17 PALS distributed nationally, equipped with Internet connectivity, teleconferencing systems, and faculty support. The distribution of students to these PALS is uneven; most of the students are from Delhi. The low number of students reflects marketing and the fact that project is still in initial stages. Despite the underwhelming enrolment in the MEIDS project to date, the mutually beneficial learning partnerships are expected to enable the university to manage the task of reaching a large and diverse population and thus to fulfil the continuing education needs of Indian managers.

\section{Computer Programmes}

From 1990 (when the first programme, the Diploma in Computers in Office Management, was launched) until 1997, the School of Computer and Information Sciences delivered its programs in print format. When the Internet become available across many cities of India, however, the School of Computer Science realized the potential of the Internet and decided to make computer programmes available online for the Certificate in Computing, Bachelor's in Computer Applications, and Master's in Computer Applications. The course content, already in print form, was converted to HTML and uploaded to the Web site. Because at the time IGNOU study centres were not equipped with computer or Internet facilities, more than 100 institutes were designated Empanelled Internet Access Points (EIAPs) throughout the country. Although these EIAP institutes do not offer courses that are recognized, accredited or affiliated to IGNOU, they provide convenient Internet access and faculty support to learners. In places where the Internet is not available, students are provided printed material and CD-ROMs. This phase of online programme development evolved into an integrated mode in 1999 when students were provided study materials in electronic form and additional support was available at regular study centres.

International Review of Research in Open and Distance Learning 


\section{Virtual Campus Initiative: Efforts to go online}

In 1999 the School of Computer and Information Sciences launched two prestigious programmes through the Virtual Campus Initiative (VCI) - the Bachelor of Information Technology (BIT) and Advanced Diploma in Information Technology (ADIT) - in collaboration with Edexcel and the Government of India Ministry of Information Technology, respectively. The deployment of VCI may be viewed as a response to recommendations of the National Taskforce on IT and Software Development [http://it-taskforce.nic.in/vsit-taskforce/ bbr3/] to achieve excellence in distance education through the creation of virtual institutions in different parts of the country. In May 1998 the Prime Minister of India appointed a National Taskforce on Information Technology and Software Development to formulate a long term national IT policy for the country. See [http://www.nasscom.org/] and follow the link "IT Policies in India." This taskforce was set up with the objective to suggest measures for India to become an IT software superpower. In association with IT Human Resources Development companies, the taskforce recommended attainment of $100 \%$ IT literacy at senior secondary level $(10+2)$ in 5 years and at secondary level in 10 years. The Taskforce also called upon all institutes offering engineering education, including polytechnics and industrial training institutes, to ascertain within 3 years the ability of all engineering students to serve in the IT enabled services sector as well as in IT industry directly.

The infrastructure provided by VCI (at the development end, learner end, and the network) was envisaged as a scalable model for higher end online IT training that meets international standards. Although access to the Internet is not yet easy or widespread, given the recommendations of the IT taskforce, the Internet appears to be poised for rapid expansion and integration within future workplaces. It is therefore expected that students with sufficient skills related to the Internet occupy advantageous positions in the job market. Education through the Internet will also provide learners current and vast information. The School of Computing Sciences has also discovered that international certification such as for Microsoft, IBM, Oracle, and so forth may also be accomplished through online examinations via the Internet.

\section{Initiation of new delivery format}

These programmes (BIT, ADIT or MEIDS project) did not exist previously in non-online format rather, since inception, have followed an Internet-centric approach, with learning resources and counselling delivered through the Internet. The Virtual Campus Initiative incorporated the following learning resources and experiences, and thus efforts were undertaken to produce (a) live satellite-based teleconferencing lectures, (b) recorded video lectures, (c) practical laboratories, (d) computer-based training tutorials, (e) learning resources accessible through 
Internet browsing, and (f) online interactive chat with peer group, faculty, and external experts.

To provide online services to the learners of BIT and ADIT, Tele-Learning Centres (TLC) were established in 1999 at institutes, organizations, and centres with computer facilities where students could perform practicals, submit assignments, write term-end examinations in supervised conditions, and participate in video-conferencing. The university decided that, to provide appropriate facilities to the learners, each TLC should have at least 50 Pentium computers as well as printers, scanners, digital cameras, colour televisions, data projectors, and microphones. In addition, TLCs were equipped to provide student access to library facilities with reference books, recorded video lectures, computer-based training and CD-ROM courseware, and access to the Internet.

In IGNOU there has been a great increase in student enrolment in computer programmes. Enrolments have grown from 484 students in 1990 to more than 100,000 students enrolled in 2000. In 1990, practicals were conducted at either Work Centres or Programme Study Centres and tens of thousands of rupees were being paid to such centres as compensation for computer hire charges. These work centres, owned by private persons, and programme study centres, situated either in colleges or private institutes, provided relevant hardware and software facilities for Certificate in Computing (CIC), Bachelor of Computer Applications (BCA) or Master in Computer Applications (MCA) students. This money was going out of the IGNOU system, which otherwise would have been spent for maintenance or updating of the university's own IT resources. Another disadvantage of such an arrangement was that because these non-IGNOU centres operate their own other programmes and accommodate their own students, scheduling theory and/or practical sessions to fit the convenience of IGNOU students was not a high priority. Consequently, to gain better control over scheduling, and utilization of machines, Regional Computer Laboratories (RCL) were established in 1999 at six regional centres in the first phase, with eight more established in August 2000. Student enrolments at these 14 RCLs are now high. They differ from TLCs and other study centres in the sense that RCLs are directly administered by regional centres, whereas TLCs are owned by private persons who may either work for IGNOU or share their facilities with IGNOU in addition to their own students. The RCLs are each provided with 30 computer systems, network connections to the Internet through leased lines and LAN, and software pertinent to the course curricula.

At each RCL a full-time consultant was appointed to look after BIT and ADIT and other computer programmes. Because the teaching mode at TLCs was student-centred, rather than teacher-centred, students contacted their counsellors through e-mail or chat mode.

Learning resources also included printed materials, daily activities for students and linkages to various other Web resources. The Faculty of Computer Sciences realized that supporting online education through the Internet requires more 
effort than the traditional approach. In a study (IGNOU, 2000) it was found that students in the first cohort who had easy access to Tele-Learning Centres found it exciting to learn online as compared to the students who did not have access to Tele-Learning Centres and who reported difficulties in pursuing the programme. The main reason for this difference was that the programme had not been designed to provide support to students in the traditional (print or offline) mode of distance learning.

Extra efforts are required to develop content for the Web, uploading to servers, and keeping track of and responding to student queries and feedback. The design of academic content of courses for Internet delivery is significantly improved from the traditional distance education approach. Although learning objectives are mentioned at the beginning of each unit in offline IGNOU courses, in the BIT and ADIT online programmes, more emphasis is placed on the importance of outcomes. Assignments are designed so as to demonstrate that expected outcomes have actually been realized. Another feature calls for learners to be informed about skills to be learned, and for online delivery, they are provided quizzes, assignments, and projects to enable them to demonstrate attainment of these learning outcomes. This model of outcome-based education in IGNOU has been borrowed and adapted from the UK education system.

\section{Consequences of Launching Online Programme Delivery}

The efforts of launching Internet-centric programmes have had both intended and unintended consequences in relation to IGNOU's institution-wide systems, course development management systems, and course delivery management systems. The aim of the Virtual Campus Initiative was to achieve democratisation of educational opportunities through nation-wide access to high quality learning resources and experiences. But this innovation has also had the unintended consequence of increasing the gap between learners residing in big and small cities, as the services of online education and the Internet are not yet available in small cities.

Because student contact with teachers is absent from the current model of Virtual Campus Initiative, students can neither see the instructor nor engage in interaction with the instructor. Pre-recorded video lectures of teachers are made available to the students at Tele-Learning Centres. However, students may interact and pose questions through e-mail or telephone to the faculty/academics at the university headquarters. As most of the learners are beginners without any computer background, they are given an online orientation via the Internet. Computer-based tutorials are made available at TLCs for basic computing programmes. 
An intended consequence of this initiative has been to move IGNOU toward a paperless style of work environment. Increased use of Internet for accessing information and working remotely, online registration, database-driven content delivery, online tutorials, online reference library, online assignment submission and evaluation are additional intended consequences of the move to online programming.

The liberation of academics in the sense that they can offer the programme from anywhere with access to the Internet, without the shelter of an institutional umbrella is another unintended consequence. The need to develop suitable mechanisms for faculty compensation and protection of intellectual property rights are additional crucial issues for the university administration.

\section{Course material}

Course materials in the traditional mode consist of printed self-instructional booklets whereas in online electronic courses, materials consist of CD-ROMs, or are provided on the Internet for downloading from IGNOU's site [www.ignou.org] in MS-Word and HTML formats. There are other differences. In a traditional IGNOU course, units form a part of a block, and a block equates to a certain number of credits. One block corresponds to one booklet and the term unit is used synonymously with the course. In traditional computer courses, terms such as course code (assigned to a particular course), blocks (collections of units), and units (individual chapters) are used. But in the case of online courses, the nomenclature is slightly different, e.g., the formal approach used with Higher National Diploma instructional design calls for course codes to be broken down into learning outcomes that in turn, are subdivided into sections or sessions. For evaluation of each learning outcome, there are specific assessment criteria based on the common skills used.

\section{Support services}

While in traditional mode students are attached to a study centre of their choice, in the Internet mode students do not necessarily go to study centres. Instead, they may have computer/Internet access either from their home or office or through an IGNOU Empanelled Internet Access Point. Tele-Learning Centres and Regional Computer Laboratories provide access to additional student support. 


\section{Counselling}

While traditional mode students attend face-to-face counselling at study centres, online students have access to counselling via the Internet. (For IGNOU, counselling, as opposed to highly course content-oriented tutoring provided by a subject specialist, refers to student-centred and problem-solving interactions provided by a person who is able to relate to the personal and individual needs of the learner.) Logging on to the IGNOU site, students may receive counselling either synchronously (chat mode) or asynchronously (e-mail).

\section{Assignments}

Students are assessed through continuous evaluation and term-end examinations. Assignments form the continuous evaluation part of assessment and carry $25 \%$ of the overall evaluation scheme. For each course there is one tutor marked assignment (evaluated by a counsellor) worth $10 \%$ and one project assignment worth $15 \%$. All assignments are compulsory and differ from traditional mode assignments. Here students can submit their assignments electronically as attachments through e-mail to either the faculty or school e-mail addresses. The online modality makes it possible for students to download corrected assignments from IGNOU's Web site at the end of a course. The term-end evaluation is worth $75 \%$ of the overall evaluation.

\section{Practicals}

Traditional mode students must participate in practicals conducted at study centres wherein the relevant hardware/software are made available to the student by the university. Internet mode students must make their own arrangements for practicals.

\section{Lead time}

For traditional programmes, the lead time (time required for programme prelaunching, including developing course material, identifying learning centres, identifying and orientating counsellors, etc.) necessary for the start of the two programme sessions per year is more than 6 months. In Internet-based programmes, programmes are offered four times a year (trimester based) and lead time is only 3 to 4 weeks.

International Review of Research in Open and Distance Learning 


\section{Management Systems}

With the deployment of new technology and delivery of learning resources and interactions, IGNOU has discovered that management structures must reflect an agenda which is target oriented, emphasises decentralisation, and readily adopts new technologies for competitive advantage. Under the new system, the control must be simple and complex - simple in the sense that the programme delivery and assessment may be manipulated from only one location, and complex in the sense that now operations may be internationalised.

\section{Implications of Online Programme Delivery}

Online delivery of programmes through the Internet is fast emerging internationally as a mode through which knowledge can be disseminated around the clock to large numbers of learners, located at geographically distant places. Under the IGNOU-Edexcel collaboration, IGNOU offers courses that match the delivery and quality norms of the Business and Technology Education Council, thus ensuring international standards of quality. Curricula are devised and regularly upgraded to keep pace with the changes in technology, market conditions, and employers' demands. Because online support is available continually, learners are not dependent on access to on-site faculty. Learners have the choice of approaching any Tele-Learning Centre of their choice.

Online delivery has implications for IGNOU administration as well. Although http and mail servers already provide Internet and intranet services to administration and faculty at headquarters, the IGNOU Web site has up until now been maintained on a rented server. After we have our own Web server, administration of Internet services will be under direct control of IGNOU. As materials can be uploaded to the server as soon as they are ready, Web delivery reduces delays in making study materials available to students. Since all course material is put on the Web for downloading by students, printing and associated costs of storing and distributing printed materials will be reduced. For up to date Web-based resources to be accessible for learners at all times, it is anticipated that effective Web administration will become a major concern.

There are also notable implications for academics. Only the most qualified will be acceptable. Not only must they be adequately prepared to develop courses in the online environment, but they must also be ready to provide timely solutions to learners' queries through chat or e-mail. Regular upgrading and evaluation of course material are other vital tasks for academics. In fact, in the open university system, it is presumed that much of the time of the faculty is spent either developing new courses or revising old courses. The usual interval for revision of non-online courses is set at 5 years, but for computer courses where the technology (and the corresponding course content) changes quickly, suitable 
mechanisms for more timely evaluation, review and revision of the academic programmes need to be put in place. When developing learning resources, academics must keep abreast of emerging international standards for online course content. Adherence to international quality norms and processes are strictly observed under the new mode of online delivery. To ensure students have the prerequisite skills, and that subsequent performance meets quality standards, appropriate mechanisms for monitoring the activities of the Tele-Learning Centres will have to be developed through the use of information technology.

\section{Prognosis for the Future}

Ayyagary and Ramalingam (2000) reported that:

If e-ducation is the future, only firms with a mixture of content, customisation, and geographical reach will be able to grab it....Surfers have to give up classroom interaction, which could take some getting used to. But online e-ducation is here to stay. (p. 60)

Having assessed the opportunities and challenges related to the possibility of offering courses over the Internet, IGNOU has decided to pursue global outreach. The university is now planning to offer online courses not only in computer programmes but also in other subjects. With its strong network of regional and study centres equipped with the latest technology, modern resources, and unmatched experience in distance learning, IGNOU finds itself in a key position to emerge as a global player in development and delivery of online education. Initially, in 1999, there were some difficulties related to launching of online programmes, particularly in the creation of Web-based content, video lectures for teleconferencing and provision of laboratories at Tele-Learning Centres, but such problems were temporary and solved by dispatching courseware CD-ROMs to students. Currently in IGNOU, approximately $10 \%$ of students are involved with online education as compared to other formats.

In creating a niche for itself in the huge market of offering online courseware, provision of online courses may be both an opportunity and a challenge for IGNOU as an institution. Internationally, various universities of USA, UK, and Europe already provide accredited and non-accredited courses online. It will be a challenge for IGNOU's Virtual Campus Initiative to stay ahead in the competitive market of providing short-term courses.

International Review of Research in Open and Distance Learning 


\section{References}

Ayyagary, N. \& Ramalingam, A. (2000, July 22 - August 6). Learning lessons at the virtual academy, Business Today, p. 60.

IGNOU, (2000). Management education through interactive delivery system: Networking through learning partnerships. New Delhi: IGNOU.

Sharma, R.C., (1999). Networked distance education in India. Indian Journal of Open Learning, 8(2), 147-156.

Citation Format

Sharma, Ramesh (January 2001) Online Delivery Of Programmes: A Case Study Of IGNOU.

International Review of Research in Open and Distance Learning: 1, 2

http://www.icaap.org/iuicode?149.1.2.11

International Review of Research in Open and Distance Learning 